[Brown, S. (1997). Special Education 2000: Developing a Policy for Inclusive Education in New Zealand. New Zealand Annual Review of Education, 6, 141-156]

\section{Special Education 2000: Developing a Policy for Inclusive Education in New Zealand}

\section{SUE BROWN}

\section{Abstract:}

Special education has had a complex history in New Zealand. The Ministry of Education's document Special Education 2000 is the latest attempt by Government to make policy and provision clear, fair and consistent. This paper examines Special Education 2000 in its historical, political and social contexts, with particular reference to the claim of the policy to be part of a government strategy for an inclusive education system.

$\mathrm{I}$

July 1996, every school in New Zealand was sent a package called Special Education 2000 (Ministry of Education, 1996). This kit contained a collection of documents relating to the government's new strategy for "a world class inclusive education system that will provide learning opportunities of equal quality to all students" (Ministry of Education, 1996). Included in the kit was a copy of the special education policy guidelines that had been released in June 1995, and reprinted versions of the two documents released in June 1996 about the proposals for Special Education 2000.

Special education has been identified as a difficult area by successive Ministers of Education, by Ministry of Education officials and, anecdotally, by almost everyone who has ever tried to grapple with understanding, resolving or explaining its complexities. Approximately $7 \%$ of the spending on school education for 1995/96 went on special education (Ministry of Education, 1996), but many commentators still assert it is either not enough or that the policies and safeguards needed to properly address issues other than funding are not yet in place (Ballard, 1996).

\section{Sue Brown}

The education reforms of 1989 have had a direct impact on how special education resources and services have been managed, and on who manages them. There have also been implications in relation to choice, accountability and market forces. There has been a concern that the theories that underpinned the education reforms would not fit the needs and complexities of special education (Mitchell, 1996).

\section{Background}

Grace (1990) characterised the process of major policy change as being one of "conflict and struggle." Whilst he was referring to the education "settlement" as a whole, his words are also very applicable to special education over the past ten years: "... most education crisis situations occur as a result of both external ideological attack and the existence of internal contradictions or weaknesses in an educational settlement" (p. 176). Special education policy development in New Zealand reflects both sorts of pressures, as an examination of the background to current policy will show.

Since the early 1970s, pressure has been put on governments in New Zealand and overseas to re-think the ways in which children with disabilities were perceived by the education system. The segregation of children from their peers on the basis of disability or difference was increasingly seen as discriminatory, unsound educational practice, and an inefficient use of resources.

In Britain and in the United States, legislation enabling students with disabilities to have access to education on a more equal footing with their non-disabled peers was enacted (PL 94-142 of 1975 in USA, Education Act 1981 in Britain), and although it came later, New Zealand's Education Act of 1989 was in fact broader, less prescriptive and therefore more enabling than other legislations.

This review does not attempt to provide an outline of the history of special education in New Zealand. Suffice it to say that by the mid1980s, there existed a wide and confusing range of provisions for children who were seen to require something more than was available in the regular school classroom. These provisions were closely tied to different categories of children (for example deaf, blind, maladjusted, slow learners, intellectually disabled) and staffed according to ratios and regulations that differed between categories. Their distribution and administration was similarly haphazard around the country. The "internal contradictions and weaknesses" were well established (Grace, 1990). 
In the two years preceding the Picot report (1988), special education was thoroughly reviewed, and a draft review report (Department of Education, 1987) was widely discussed. A policy statement on mainstreaming was produced in 1988, but the sweeping reforms of education as a whole overtook further development of special education policy. Despite the legislative changes brought about by the 1989 Education Act, the new Ministry of Education did not immediately develop policy to meet the changed legal climate or the changes in school-based provisions under Tomorrow's Schools (1988).

The Ministry of Education wrote a draft document early in 1991 which was (unofficially) circulated widely, followed in November of the same year by an official Statement of Intent. This was followed by two years of Special Education Policy Implementation Team (SEPIT) consultations around the country, a process that used a great deal of time and energy on the part of many and varied groups and individuals with an interest in the issues, and resulted in a report that was never officially released by the Minister of Education.

\section{The Segregation/Integration Debate}

In words that echo Grace, Skrtic (1991) noted, in relation to special education, that "... change demands can arise externally, when values change in society, or internally, through an accumulation of anomalies ..." (p. 210). The "values change in society" (or the "external ideological attack") in relation to the education of students with disabilities had been coming for a long time, and was seen in such broad movements as the deinstitutionalisation of people with intellectual disabilities, and the slow recognition of their rights. Much of the academic debate and research that has influenced educators and policy makers here has come from the United States, Canada and Britain, and as Michael Oliver observes in Understanding Disability (1996), "the most important issue in respect of the education of disabled children over the last twenty years has been that of integration"(p. 78).

Stainback and Stainback (1984) argued for a merger of special and regular education on the grounds that there were not two different types of students ("special" and "regular"), and that there were not two different sets of instructional methods. They noted that "regular education has a history of being reluctant to meet the needs of all students" (p. 110), and pointed out that discrimination can be sanctioned when some students are excluded.
Gartner and Lipsky (1988) stated "... there is no compelling evidence that special education programs have significant benefits for students. On the contrary, there is substantial and growing evidence that goes in the opposite direction" (p. 375).

Bellamy (1989), commenting on Gartner and Lipsky, refers to the paradigm shift represented by the move to "... reconceptualise school reform efforts so that all children are included" (p. 245).

In Britain, the Warnock Report of 1978 heralded a change from categorising students according to their disability, to a focus on their individual needs. The report also contained "the notion ... that all teachers are teachers of pupils with special educational needs" (Visser, 1993). Much has changed in Britain since then, and writers such as Barton (1993) provide analyses of the extent to which special education policies have been able to bring about integration of students with special needs in an education system that has undergone radical change. Whilst not all commentators are so pessimistic, Barton (1993) predicts that in the new education climate in Britain, "The extent to which schools will be welcoming institutions to all pupils irrespective of disability, race, gender or class will be seriously challenged.... Rather than inclusive educational provision, more segregated schooling will develop" (p. 39).

Dyson and Millward (1996) identified internal and external pressures that impact on the ability of schools to include all students successfully. They point out unresolved dilemmas such as the conflicts that can arise between "meeting the needs of each [child]" and "teaching to all [children]". They also state that "the tensions in schools are exacerbated by the marketisation of schooling brought about by the 1988 Act."

Writing about advocacy and inclusion in Australia, Goninan (1995) noted that "special education policy has moved in the direction of inclusive approaches to service delivery" but that "all [states] have adopted policies that allow for the status quo (a dual system of inclusion and segregation) to be preserved" (p. 21). She concludes by conceding that "Australian schools will continue to move towards inclusion of students with disabilities", but that what will be important "is the quality of service offered, and the minimisation of negative attitudinal consequences of poorly implemented inclusion" (p. 32).

In New Zealand, Ballard (1996) has consistently argued for an inclusive system of education that challenges "discriminatory practices, values and paradigms" (p. 42). Mitchell (1996) identifies and discusses 
the negative consequences of the New Zealand educational reforms (both real and potential) for students with special educational needs. He urges the special education community and policy makers to examine these and "to find ways to make the reforms work for students with special educational needs" (p. 72).

A group representing IHC, NZCCS, the Royal New Zealand Foundation for the Blind and the Special Education Service visited Sweden, Denmark and Canada in 1990 and published their report on the visit as a document entitled Inclusive Education for All. In this, they set out their "vision of inclusive education for New Zealand" (Interagency Group, 1990). The Special Education Service had also prepared documents of policy on inclusive education in 1990, supporting "... the right of all learners to share the same learning environment as their age-mates or peers within their local community and to be properly supported in doing so" (SES, 1990).

\section{Policy Directions, Reforms and Resources}

Whilst the imperatives for increased integration of students with special educational needs had clearly been established by the late 1980s, the structural and resource implications were far from clear. Funding is a central issue in special education policy development, closely related to strategies designed to discover who and what should be funded. Writing in 1984, Edgar and Hayden ask "Who are the children special education should serve and how many children are there?" Edgar and Hayden suggest that categorising the services that are beneficial to children may be a more realistic approach. They refer to research done on the over-representation of minorities in special education that indicates "... there is evidence that the schools (rather than the children's performance) are the cause of the labelling" and that "changes in definition of mental retardation have come most often from changes in social and political ideology rather than from scientific research" (p. 532).

The reluctance of governments to take a strong leadership role in relation to the education of students with disabilities reflects an ambivalence about the purposes of education. Skrtic (1991) points out that there is "an inherent contradiction between the democratic ends and the bureaucratic means of public education" (p. v). Mitchell (1996) also suggests that there are more fundamental questions that will need to be asked "as education systems are being designed to be fully inclusive and enhancing of the quality of all children's lives" (p. 72).
With the devolution of management to individual schools, using roll numbers as a basis for funding, has come increased competition between schools for pupils - particularly those seen as desirable in terms of anticipated examination passes (Lauder et al., 1994). Mittler (1993) states that in a climate of open competition between schools for pupils, "children with special education needs may not be wanted and may well be singled out for exclusion or removal to segregated provision 'for their own good" " (p. 27). Barton (1993) is just as blunt: "Schools in a free market should be able to choose their customers. Particular pupils will not be welcome at particular schools because they will be viewed, for example, as unsuitable material ... ultimately damaging to the status of the school" (p. 36)

\section{Maori Perspectives}

There is very little published on Maori perspectives of special education, particularly in relation to changing government policies. Bevan-Brown's 1989 research project, which examined intellectual disability from a Maori perspective, was prompted by her own frustration at this very scarcity. Her paper included a discussion of mainstreaming, and she found that most of her interviewees "believed in the mainstreaming of intellectually disabled children into regular classrooms" (Bevan-Brown, 1995 , p. 224). Their concerns were very similar to those of Pakeha parents - they stressed the need for the resources necessary to achieve successful mainstreaming. Her interviewees also shared the view Bevan-Brown thought was a Pakeha one, that "the intellectually disabled should be taught the necessary skills to enable them to live as independent a life as possible" (p. 227). The differences in perspective she discovered related to more general differences about education and the concerns Maori parents have about education for all their children.

Presentations at a hui in Dunedin in 1988 (Te Roopu Manaaki I Te Hunga Haua) made the point that "culturally sensitive alternatives provided within the mainstream must not only be considered, they must be implemented, and with the full participation of Maori at all levels of decision making." One of the eight recommendations from the hui was that "Maori children with disabilities should have their culture and language affirmed in the education system and community as a whole"(p. 26).

Moltzen and Mitchell (1992) found that their small group of Maori respondents saw mainstreaming as very acceptable from a Maori perspective. 
Research being undertaken by Tawhiwhirangi $(1996)^{1}$ indicates that Maori concerns are mostly to do with adequate representation and resources, but an interesting early finding is the "confusion by non-Maori of making a distinction between special education needs, and special educational needs of Maori" (p. 9).

\section{Special Education 2000: What Does it Contain?}

Special Education 2000 incorporates the Special Education Policy Guidelines released by the Minister of Education in June 1995, as well as strategies for achieving the government's goal of "a world class inclusive education system."

The Special Education Policy Guidelines are based on seven principles, and are designed to "assist early childhood services and schools achieve [National Education Goals 1,2,4, and 7] which form part of the National Education Guidelines." The principles focus on "learners with special needs" and provide outlines of responsibilities for early childhood services, schools, and central agencies.

The new initiatives announced in Special Education 2000 in July 1996 are the Special Education Grant (SEG), and the Individual Entitlement (IE). They apply only to the compulsory education sector, although the Ministry's stated intention is to develop strategies to ensure the policy is eventually enacted at early childhood and tertiary levels. The SEG is a grant that will be paid to all schools starting in 1997. It will be based on total roll numbers, on a sliding scale according to the socio-economic status of the school's catchment area.

The Ministry has calculated that approximately 2 percent of the school aged population will have "high or very high" support needs. This group of students is to be funded on a new system: the Individual Entitlement. The intention is to provide a guaranteed level of resourcing, no matter which school students are enrolled in. It will transfer with students if they move to another school. The introduction of this system is planned for 1998, and in the meantime, most students who have up until now received special education discretionary assistance (SEDA) will have their level of resourcing maintained. The group of students who will be eligible for Individual Entitlement are roughly identical with the group currently receiving SEDA.

The final part of the Special Education 2000 policy package is the promise of "information, education and specialist advisory support to assist families, schools and teachers achieve the best possible learning environment for all students with special education needs" (Ministry of Education, 1996).

The whole plan is to be phased in over three years, using the extra 55 million dollars allocated in the May 1996 Budget. Its development will be overseen by the National Advisory Committee on Special Education (NACSE) established by the Minister of Education in 1995.

\section{Analysis of Special Education 2000}

Codd (1988) noted that "policies are produced in response to the failure of other policies leading to what Offe refers to as crises of crisis management" (p. 237). The development of special education policy over the last ten years reveals a variety of attempts to deal with the problems and the crises of special education.

\section{The political and economic contexts}

It is important to "deconstruct" (Codd, 1988) this policy to examine the ways in which the historical, political and social contexts in which it is set have influenced its design, and to uncover the ideological framework behind it. Special education has always been a political issue: the intense lobbying that has been the background to all changes in policies over the last ten years in particular is evidence of this.

The economic aspects of the political context reflect the changes that have occurred in New Zealand in the last ten or more years, as the country has shifted from a welfare state to a market-driven economy. In education, the reforms of 1989 led to a devolved system of decision-making and management. While schools have been largely positive about their increased responsibilities (Wylie, 1994), they have had reservations about the extent of some of them, and provision of support for students with special needs has been one such area.

The proposed Special Education Grant to schools can be seen as consistent with the devolution of decision-making to the basic unit of the compulsory education system - the school. Given that schools and communities welcomed the control and flexibility Tomorrow's Schools gave them, it could be expected that this additional funding will be welcomed as a means to address needs that have may have been neglected. It could help address some of the problems identified by Lauder et al. (1994) in that poorer schools will receive proportionally more funding than richer schools. The amount of the grant, however, is not great, even at the highest level ( $\$ 34.50$ per pupil at Decile 1 ) and may not be enough to make real differences. 
The introduction of Individual Entitlements for students whose support needs are much higher than those a school could reasonably be expected to meet, even with the SEG, makes an interesting contrast with the ideology behind the SEG. Rather than simply funding all schools at a higher level through SEG, this part of the policy holds back some control at the centre. The most obvious reason for doing this is a recognition of the fact that students with high support needs are not evenly distributed across schools: some schools may have no such students, other may have several. It also acknowledges the difficulties that exist when resources are tied up in the special school/unit system.

Another reason for maintaining central control of this funding, however, could be to ensure that the equity intended is not lost by leaving already-vulnerable students at the mercy of local decisions that may not be in their best interests. In a market economy, where education is seen to be a means to personal and state economic ends (Treasury, 1987), there is a real danger that those with the label "special" will not be seen as worthy of a large amount of scarce resource allocation. Writing of similar problems in Britain, Bines (1995) sees special education policies as entering into the market place, but with "some acknowledgment that the market has to be regulated if its benefits for certain users are to be demonstrated and its most problematic consequences curtailed" (p. 160).

\section{Social contexts: Special education policy and students with disabilities}

From the 1987 Draft Review onwards, all policy statements could be characterised as integrative to some extent. They have attempted to find ways of making provision for change in a system that had never been totally segregationist, but which had for the most part developed quite separate strands for students with and without disabilities. For example, the 1988 policy statement on mainstreaming (Department of Education, 1988) states: "The principal objective of mainstreaming is to cater for the educational needs of all young people with handicaps within regular school settings where this is appropriate and practicable." The use of terminology that Fulcher (1989) would assign to a medical model of disability meant that the control still remained in the hands of those professionals (Principals, Inspectors of Special Education) who were seen to know what was best for students.

The 1991 Statement of Intent made extensive use of the word "choice", but the choices were limited by the availability or otherwise of special education facilities. This could be construed as a reluctance on the part of government to actively promote an inclusive education system. By failing to provide a mechanism to ensure the choice of an inclusive setting was supported with resources of equal quantity and as secure as those in segregated settings, the Ministry was in effect making parents responsible for policy.

Special Education 2000 contains the mechanism in the concept of IE for a stronger movement towards real choice, and therefore towards a more acceptable settlement of the crisis of management (Codd, 1988) in the education of students with disabilities. If funding travels with students, rather than being locked into a segregated system, parents gain choice both as exit (for example, from a segregated setting) and as voice (in, for example, regular settings). This is what Gordon (1995) described as "choosing across", and it offers the hope of achieving desirable outcomes for parents, schools and students.

The IE mechanism also offers hope to parents who want their children to be educated in segregated settings for cultural reasons. As Ballard (1996) points out, "the right to inclusion does not mean that individuals or groups have to take part and some may choose separate provisions in order to retain their identity and culture". He cites the examples of Maori and the Deaf community, two groups that have cultural, pedagogical and political reasons for choosing separate provisions. Strong lobbying has occurred from parents and educators who want separate provisions maintained for these reasons.

\section{Social contexts: Enlarging the net}

The extent to which special education funding can be stretched to encompass an increasing number of students (and schools) experiencing difficulties is another example of the problematic nature of policy development. This reflects, to a large extent, the social context in which the policy will operate. Students who are failing in the school system (or schools that are failing students) have put special education provisions under increasing pressure. Policies developed over the past ten years (such as an increase in the number of Guidance Learning Units in schools) have gone some way towards addressing the issues, but there are complex social and political issues involved which would require major changes to much more than the education system.

Provisions which tie resources to individual students can tend to overlook the influence that school policies and practices have on such students. Fulcher (1989), referring to the "20\% of schoolchildren [claimed to] ... have special educational needs", says "An alternative 
politics would focus on school practices and suggest that for a large proportion of these children, the deficit lies in failure of pedagogic practices" (p. 42). Special Education 2000's proposals for information and education will be hard-pressed to turn around some of the more resistant attitudes in our schools, and it remains to be seen how schools will choose to use their SEG.

In Britain, a tendency to increase the number of students with "statements" (roughly equivalent to the IE scheme) has been seen as a result of internal market pressures on schools (Bines, 1995). When resources are limited, there will indeed be pressure to identify as many students as possible to receive IE and thus both free up and attract more resources within the school. The mechanisms for iden tification will need to tread the fine line between being overly categorical, and too open to broad interpretation.

The proposals of the Statement of Intent and those of the subsequent Special Education Policy Implementation Team (SEPIT) were cumbersome, involving highly contentious ideological and industrial issues. In particular, the proposal to make the Special Education Service contestable "met with widespread opposition and did not proceed" (Mitchell, 1996).

In some ways Special Education 2000 is similar to the Statement of Intent, but there are fundamental differences, most notably the attachment of resources to individuals who have high support needs, no matter where they are educated, and the provision of assistance to all schools for meeting moderate special needs. The wholesale removal of one type of resource (specialist teachers) to be replaced by what schools saw as a lesser resource has been abandoned. Special Education 2000 (as outlined so far) does not take anything away from schools - it adds to their resources.

\section{Rights and policy development}

Special Education 2000 represents a large step along the way to policy that is based on a rights discourse (Fulcher, 1989), rather than one that seeks to "fix" individual problems. The SEG in particular, encourages schools to shift the focus onto whole school policies and practices. Whilst the IE component could be seen to be a return to labelling, it has the potential to be a protection of rights and, because of its portability, it will enable a greater exercise of rights ( to regular school enrolment, for example) than the current system.
Fulcher (1989) also outlines ways in which the objectives of policies can be revealed by the ways in which they approach the theme of integrating students with disabilities. Using her analysis, Special Education 2000 can be seen as "... defining integration as a process of increasing the participation of all students in the social and educational life of regular classrooms" [original emphasis, p. 51]. Special Education 2000 does not however directly address the issue of curriculum, and both Fulcher and Oliver (1996) argue that the debate about where students with disabilities should be educated must not overshadow the importance of what their education should look like. Again, the only glimmer of hope that Special Education 2000 will address this issue is the provision for "information and education."

\section{Commentary}

Special Education 2000 is a policy in development, and some of the most crucial elements are still being developed. Nevertheless, it is possible to make some comments on the policy's directions, implications, strengths and weaknesses.

The policy appears to be a move in the right direction if New Zealand is to achieve an inclusive society. It will encourage and support schools to take responsibility for all students, by providing extra funding in the form of Special Education Grants and Individual Entitlements. It will give parents the freedom to make choices for their children with disabilities, based on a more equitable way of providing and accessing support.

The key factors that will affect how well the policy succeeds in achieving its goals are the details and adequacy of the IE scheme, the adequacy of the SEG, the effectiveness of the Ministry's information and education programme, the willingness of schools to take up the challenge to be responsible for all students by using innovative, cooperative strategies, and the extent to which it enables Maori to take initiatives that fit their kaupapa.

The policy is vague on the continued availability of specialist resources, with no mention made of any plans to make the Special Education Service contestable, as has been proposed several times in the past six years. The likelihood of this policy succeeding depends on schools feeling they are gaining rather than losing resources, and that the specialist support currently available will not be removed or have a cost attached. 
The details of the IE that will be most crucial to its success or failure are those to do with who gets entitlement, how decisions about entitlement will be made, how much the entitlement will represent, how the funds will be managed, how funding will transfer from setting to setting (especially from special to regular schools) and how the scheme will be monitored to ensure it is achieving the intended outcomes. The way in which the needs of students who approach but do not reach IE status are met will be another factor in the success or failure of the new policy. Whatever methods are used to identify students for IE, they must be fair, valid, reliable and acceptable to parents as well as educators.

Truly inclusive schools will only come about when we stop talking about "special education" and "special needs" altogether, and "focus on ways of creating the conditions that will facilitate and support the learning of all children" (Ainscow, 1993). This is a more complex endeavour than simply identifying and funding individual students, but it is the only way to bring about real change for all students.

Slee (1995) says that "schools have a choice. Simply put, they can either enable or disable students; they can include or exclude." The proposals contained in Special Education 2000 hold out some hope that schools may at least be relieved of some of the resource-finding problems, but attitudinal and pedagogical change will not necessarily follow. Far too many schools are still "disabling" and excluding students from a meaningful education. Every school now needs an underlying philosophy that values all students, and that believes all students have a right to a quality education.

\section{Note}

1. Tawhiwhirangi, Keriana. (1996). Special education issues: possible solutions. Personal communication, 23 October 1996.

\section{References}

Ainscow, Mel. (1993). Beyond special education: Some ways forward. In Visser, J. \& Upton, G., Special education in Britain after Warnock. London: David Fulton Publishers Ltd.

Ballard, Keith. (1990). Special education in New Zealand: Disability, politics and empowerment. International Journal of Disability, Development and Education, 37(2), 109-124.
Ballard, Keith. (1996). Inclusive education in New Zealand: Culture, context and ideology. Cambridge Journal of Education, 26(1), 33-45.

Barton, Len. (1993). Labels, markets and inclusive education. In Visser, J. \& Upton, G., Special education in Britain after Warnock. London: David Fulton Publishers Ltd.

Bellamy, G. Thomas. (1989). School reform for all students: An essay review of "Beyond separate education". Journal of the Association for Persons with Severe Disabilities, 14(3), 241-245.

Bevan-Brown, Jill. (1995). Intellectual disability: A Maori perspective. In Ballard, K., Disability, family, whanau and society. Palmerston North: Dunmore Press.

Bines, Hazel. (1995). Special education needs in the market place. Journal of Education Policy, 10(2), 157-171.

Birch, Rt. Hon. W. (1996). Budget 1996. Wellington: GP Print.

Codd, John A. (1988). The construction and deconstruction of educational documents. Journal of Education Policy, 3(3), 235-247.

Creech, Hon. Wyatt. (1996). Extra $\$ 55$ million for special education. Budget 1996 Press Release, Wellington.

D.E.S. (1978). Special education needs: Report of the Committee of Enquiry into the education of handicapped children and young people (Warnock Report). London: HMSO.

Department of Education. (1987). Draft review of special education. Wellington: Department of Education.

Department of Education. (1988). Mainstreaming. Supplement to the Education Gazette, 2 May.

Dyson, Alan \& Millward, Alan. (1996). Innovatory special needs practice in UK mainstream schools. Paper presented at 18th World Congress of Rehabilitation International, Auckland, New Zealand, 15-20 September.

Edgar, Eugene \& Hayden, Alice H. (1984). Who are the children special education should serve and how many children are there? Journal of Special Education, 18(4), 523-539.

Fulcher, Gillian. (1989). Disabling policies? A comparative approach to education policy and disability. Lewes: Falmer Press.

Gartner, A. \& Lipsky, D. K. (1987). Beyond special education: Towards a quality system for all students. Harvard Education Review, 57, 367-395.

Goninan, Margaret. (1995). Advocacy and inclusive education: an analysis of political forces affecting educational service delivery to students with disabilities. Australian Disability Review, 2, 20-33. 
Gordon, Liz. (1995). Is school choice a sustainable policy for New Zealand?: A review of recent research findings and a look to the future. New Zealand Annual Review of Education, 4, 9-24.

Grace, Gerald. (1990). The New Zealand Treasury and the commodification of education. In Middleton, S., Codd, J., \& Jones, A. (Eds.), New Zealand education policy today: Critical perspectives. Wellington: Allen and Unwin.

Interagency Group. (1990). Inclusive education for all. Report of the interagency visit to Sweden, Denmark and Canada, OctoberNovember 1990. Wellington: Interagency Group.

Lange, David. (1988). Tomorrow's schools. Wellington: Government Printer.

Lauder, H., Hughes, D., Waslander, S., Thrupp, M., McGlinn, J., Newton, S. \& Dupuis, A. (1994). The creation of market competition for education in New Zealand: Smithfield Project. Wellington: Ministry of Education.

Minister of Education. (1995). Special education policy guidelines. Wellington: Office of Minister of Education.

Ministry of Education. (1991). Educational provision for learners with special needs: A review of policy. Wellington: Ministry of Education.

Ministry of Education. (1991). Special education in New Zealand: Statement of intent. Wellington: Learning Media.

Ministry of Education. (1996). Special Education 2000. Wellington: Ministry of Education.

Mitchell, David R. (1996). The rules keep changing: Special education in a reforming education system. International Journal of Disability, Development and Education, 43(1), 55-74.

Mittler, Peter. (1993). Special needs at the crossroads. In Visser, J. \& Upton, G., Special education in Britain after Warnock. London: David Fulton Publishers Ltd.

Moltzen, Roger \& Mitchell, David. (1992). Monitoring today's schools: Report Number 6 -Children with special needs. Wellington: Ministry of Education \& University of Waikato.

New Zealand Government. (1989). Education Act. Wellington: Government Printer.

New Zealand House of Representatives. (1995). Inquiry into children in education at risk through truancy and behavioural problems: Report of the Education and Science Committee. Education Gazette, 2March.

Oliver, Michael. (1996). Understanding disability: From theory to practice. Basingstoke: Macmillan Press Ltd.
Porter, Gordon L. (1988). The Regular Education Initiative: The debate over educational reform. New York: Syracuse University.

Skrtic, Thomas M. (1991). Behind special education: A critical analysis of professional culture and school organisation. Denver: Love Publishing Company.

Special Education Policy Implementation Team. (1993). Final report. Wellington: SEPIT.

Special Education Service. (1990). Including all learners in regular education. Wellington: SES.

Stainback, William \& Stainback, Susan (1984). A rationale for the merger of special and regular education. Exceptional Children, 51(2), 102-111.

Taskforce to Review Education Administration. (1988). Administering for excellence. (Picot Report). Wellington: Government Printer.

Te Roopu Manaaki I Te Hunga Haua. (1988). Bicultural issues in community integration for persons who have intellectual disabilities: Implications of the Treaty of Waitangi. Conference presentations, New Zealand Institute of Mental Retardation, Dunedin.

The Treasury. (1987). Government management brief to the incoming government 1987: Volume II, Education issues. Wellington: Government Printer.

Visser, John. (1993). A broad, balanced, relevant and differentiated curriculum? In Visser, J. \& Upton, G., Special education in Britain after Warnock. London: David Fulton Publishers Ltd.

Weiler, Kathleen. (1988). Women teaching for change. Massachusetts: Bergin \& Garvey.

Wylie, Cathy. (1994). Self-managing schools in New Zealand: The fifth year. Wellington: New Zealand Council for Educational Research.

\section{The author}

Sue Brown is the Education Advocate for IHC New Zealand Incorporated, and has a background in special education. As principal of Clareville Special School she oversaw its closure and then worked for four years as Support and Resource Adviser in the Wairarapa. She has worked for IHC's Advocacy Centre for three years, advocating for the inclusion of students with disabilities in regular schools and classes. 